Farum

Sociológico

\section{Forum Sociológico}

Série II

$30 \mid 2017$

Internet e ativismos em saúde

\title{
Ciberativismo como instrumento de proteção socioambiental no Brasil em Espanha
}

Ciberativism as instrument of socio-environmental protection in Brazil and Spain

Mariana Olívia Santana dos Santos, Thialisson Santos Ribeiro, José Marcos da Silva, Isaltina Maria de Azevedo Mello, Idê Gomes Dantas Gurgel e Lia Giraldo da Silva Augusto

\section{CpenEdition}

\section{Journals}

Edição electrónica

URL: https://journals.openedition.org/sociologico/1758

DOI: 10.4000/sociologico. 1758

ISSN: 2182-7427

Editora

CICS.NOVA - Centro Interdisciplinar de Ciências Sociais da Universidade Nova de Lisboa

Refêrencia eletrónica

Mariana Olívia Santana dos Santos, Thialisson Santos Ribeiro, José Marcos da Silva, Isaltina Maria de Azevedo Mello, Idê Gomes Dantas Gurgel e Lia Giraldo da Silva Augusto, «Ciberativismo como instrumento de proteção socioambiental no Brasil em Espanha», Forum Sociológico [Online], 30 | 2017, posto online no dia 30 dezembro 2017, consultado o 29 março 2022. URL: http:// journals.openedition.org/sociologico/1758 ; DOl: https://doi.org/10.4000/sociologico.1758 


\title{
CIBERATIVISMO COMO INSTRUMENTO DE PROTEÇÃO SOCIOAMBIENTAL NO BRASIL E EM ESPANHA \\ CYBERACTIVISM AS INSTRUMENT OF SOCIO-ENVIRONMENTAL PROTECTION IN BRAZIL AND SPAIN
}

\author{
Mariana Olívia Santana dos Santos \\ Fundação Oswaldo Cruz, Instituto Aggeu Magalhães, Laboratório de Saúde, Ambiente e Trabalho \\ Thialisson Santos Ribeiro \\ Fundação Oswaldo Cruz, Instituto Aggeu Magalhães, Laboratório de Saúde, Ambiente e Trabalho \\ José Marcos da Silva \\ Fundação Oswaldo Cruz, Instituto Aggeu Magalhães, Laboratório de Saúde, Ambiente e Trabalho \\ Isaltina Maria de Azevedo Mello \\ Universidade Federal de Pernambuco, Departamento de Comunicação Social \\ Idê Gomes Dantas Gurgel \\ Fundação Oswaldo Cruz, Instituto Aggeu Magalhães, Laboratório de Saúde, Ambiente e Trabalho \\ Lia Giraldo da Silva Augusto \\ Fundação Oswaldo Cruz, Instituto Aggeu Magalhães, Laboratório de Saúde, Ambiente e Trabalho
}

\begin{abstract}
Resumo
Nos últimos anos, mudanças profundas no modo de construção e reconstrução das relações sociais e políticas vêm acontecendo com o advento da internet. As Tecnologias de Informação e Comunicação configuram novas sociabilidades, relacionamentos e valores culturais, exercendo influência direta nos sistemas políticos, ao possibilitar novas formas de atuação, articulação e ação. Este trabalho tem como propósito analisar o Índice de Participação Política e Infuência de dois movimentos socioambientais relacionados à resistência popular frente às nocividades à saúde e injustiças socioambientais decorrentes da implantação de refinarias de petróleo e sua busca por espaço e legitimação institucional. O ciberativismo possibilita aprendizado, produção de conhecimento, troca de saberes e visibilidade dos sujeitos e territórios, apoiando-se nos conceitos de cidadania e de justiça ambiental.
\end{abstract}

Palavras-chave: ciberativismo, comunicação e saúde, comunicação ambiental, saúde ambiental

\begin{abstract}
In recent years, profound changes in the way of building and rebuilding social and political relations have been happening with the advent of the internet. The Information and Communication Technologies configure new sociabilities, relationships and cultural values, exerting direct influence in the political systems, allowing new forms of action, articulation and action. The purpose of this paper is to analyze the Politics and Participation Influence Index (IPPI) of two socioenvironmental movements related to the popular resistance to social and environmental harmfulness and injustices arising from the oil refineries implementation and their search for space and institutional legitimacy. The cyberactivism allows learning, knowledge production, exchange of knowledge and visibility of subjects and territories, based on the concepts of citizenship and environmental justice.
\end{abstract}

Keywords: cyberactivism, communication and health, environmental communication, environmental health 
Vulnerabilização e ciberativismo socioambientais diante da indústria do petróleo

O processo de globalização, entendido como a configuração dos mecanismos de acumulação do capital a partir dos processos de descentralização das operações produtivas e centralização do capital (Chesnais e Serfati, 2003), resulta não só na promoção dos investimentos e atividades produtivas, mas no aumento do consumo de atividades energéticas.

No Brasil, com o lançamento do Programa de Aceleração do Crescimento (PAC), em 2007, cujo maior aporte financeiro é destinado ao petróleo e ao gás natural ( $R \$ 179$ bilhões), tem-se notado amplos investimentos na construção e modernização de complexos portuários e refinarias de petróleo (Brasil, 2013). Embora declinante ao longo do tempo, Cavalcanti (2008) afirma que o petróleo ainda representa cerca de $40 \%$ da energia consumida no planeta (Cavalcanti, 2008).

Rigotto (2008) aborda a problemática de uma configuração mais recente das indústrias no mercado mundial orientada pelo capitalismo liberal, cujo investimento em indústrias de alto poder poluidor diminui nos países centrais (onde observa-se melhora na conscientização ecológica, legislação ambiental e organização social) e aumenta nos países periféricos, aproveitando-se de "vantagens competitivas como solo barato, incentivos fiscais, mão de obra barata e dócil, e sociedades mais frágeis em sua organização" (Rigotto, 2008).

As questões na dimensão da saúde e do ambiente no planejamento de grandes empreendimentos econômicos são tradicionalmente relegadas para o plano secundário. Os recursos naturais, os riscos tecnológicos e ambientais gerados pelos processos de produção e consumo, a degradação ambiental e os agravos que causam à saúde são distribuídos de forma desigual no espaço, entre os segmentos sociais. Conforme relatado por Silva et al. (2013), os processos para obtenção do licenciamento ambiental, como a elaboração de Estudo de Impactos Ambiental (EIA), são mal elaborados, pois não observam a complexidade do território e nem analisam aspectos culturais, econômicos, ambientais e sanitários, bem conhecidos e respaldados cientificamente (Silva et al., 2013).

A indústria do petróleo é um dos empreendimentos com maior potencial poluidor, seja na atmosfera, nas águas e ou no solo - o que contribui para uma contaminação não apenas localizada, mas em escala global, gerando impactos negativos ao ambiente e à saúde das populações e interferindo ativamente, também, nas mudanças climáticas e no aquecimento global.

Um dos aspectos mais críticos relacionados à implantação de grandes empreendimentos, em par- ticular da cadeia do petróleo, é o ocultamento dos problemas e das mudanças que seus processos de construção trazem para as vidas das pessoas, além da ausência de participação esclarecida sobre as transformações do território onde vivem e trabalham seus habitantes (Santos et al., 2012).

Nesses locais, observam-se mudanças no perfil epidemiológico regional, alteração dos ecossistemas, crescimento desordenado de aglomerados urbanos, aumento da violência, emergência de novas doenças e re-emergência de doenças erradicadas, além de processos de desterritorialização, desemprego (ao término das obras), poluição e favelização (Gurgel et al., 2009; Rigotto, 2007). As comunidades são excluídas do processo de discussão e decisão sobre a nova reconfiguração econômica e produtiva do território e populações tradicionais, como povos indígenas, comunidades quilombolas, agricultores e pescadores artesanais, são postos em situação de vulnerabilidade, com potencial para sofrer danos, ou de vulneração, condição dos que já sofreram o dano (Domingues et al., 2014).

O desequilíbrio na manifestação das vozes dos vulnerados desse território pelo poder econômico é evidenciado pelos grandes meios de comunicação social, que propagandeia apenas o bônus dos empreendimentos econômicos e oculta o ônus social, fragilizando a resiliência da população a essa ideologia desenvolvimentista (Domingues et al., 2014; Marques, 2014; Pacheco e Porto, 2009; Santos et al., 2016).

As populações vulnerabilizadas, em face dos processos de injustiça ambiental, organizam-se em movimentos sociais. Para Manuel Castells (2015), os movimentos sociais se definem como articulações da sociedade civil constituídas por segmentos da população que se reconhecem como portadores de direitos, os quais ainda não se efetivaram na prática, e que podem ser classificados como legitimadores, ou seja, instituídos pelas instituições dominantes; de resistência, quando atuam em oposição às estruturas de dominação; ou de identidade de projeto, quando o que está em jogo é a construção de uma nova identidade redefinindo sua posição na sociedade (Castells, 2015).

Peruzzo (2010) enfatiza que as pessoas buscam soluções para os seus problemas e recursos alternativos, organizando-se em grupos formais e informais ao redor de reinvindicações e interesses coletivos, utilizando estratégias e tecnologias produtoras de espaços democráticos que possibilitem a politização da informação e a luta pela cidadania para suprir as necessidades dos indivíduos e da sociedade, além da garantia do direito humano à comunicação (Peruzzo, 2010).

A comunicação possibilita aprendizado, produção de conhecimento, troca de saberes, formas e expressões de vida e torna os problemas visíveis, 
facilitando que mais atores e instituições se articulem para sua resolução e que os sujeitos das comunidades envolvidas no problema possam ter um papel ativo nos processos decisórios.

Nesse contexto, os movimentos ambientais são portadores de uma queixa histórica sobre o silenciamento por parte dos meios de comunicação sociais tradicionais em relação às suas causas, protestos e reinvindicações. Autores reconhecem que estes meios de comunicação tendem a apresentar pontos de vista pouco heterogêneos e que priorizaram os seus financiadores (anunciantes privados e estatais), em detrimento da diversidade de sujeitos e pontos de vista que compõem a sociedade (Guareshi, 2013; Peruzzo, 2010).

Nos anos 1990, com o avanço tecnológico e o surgimento da internet, modificou-se drasticamente a forma de interação social, influenciando novas dinâmicas no campo político, econômico e simbólico, levando a movimentos profundos de construção e reconstrução das relações sociais e políticas, local e globalmente.

A comunicação e a troca de informações deixam de ser unidirecionais e hierárquicas, de cima para baixo, e tornam-se multidirecionais, transitando por diversos sentidos e caminhos. Isso altera não apenas a forma de fazer política, mas também a própria sociedade que se apropria da internet transformando-a em um novo espaço estratégico de comunicação e disputa simbólica, pois, devido às suas características técnicas, permite que as organizações da sociedade civil desenvolvam estratégias de visibilidade que ampliem sua capacidade de articulação, organização e mobilização política (Castells, 2015).

Com as Novas Tecnologias de Informação e Comunicação (NTIC), o espaço virtual tem sido estratégico para manifestações, compartilhamento de lutas, causas, protestos e para mobilização da opinião pública. Isso representa uma nova forma de participação democrática influenciada pela velocidade na transmissão das informações, pela interatividade e pela arquitetura de comunicação horizontal organizada em rede que influencia os sistemas políticos, ao possibilitar novas formas de atuação e ação de atores políticos nas arenas públicas (Araújo et al., 2015).

O ciberativismo se confunde com o próprio desenvolvimento da rede mundial de computadores e influenciou decisivamente grande parte da dinâmica e das definições sobre os principais protocolos de comunicação utilizados na conformação da internet (Silveira, 2010).

O marco inicial do ciberativismo foram as revoltas zapatistas em 1994, no sul do México, que representaram uma verdadeira "revolução das revoluções", por terem sido inspiração para uma nova forma de resistência em que a comunicação e a prática midiáticas têm papéis centrais. Os protestos anticapitalistas, que culminaram midiaticamente na Batalha de Seattle em 1999, são compreendidos como sendo o desenvolvimento do ciberativismo porque constituiu-se em manifestações contra as políticas neoliberais globalizantes, que ocorreram durante a reunião da Organização Mundial do Comércio (OMC), cujos protestos ganharam repercussão midiática e marcaram a emergência do movimento antiglobalização enquanto um ator mundial (Bringel e Muñoz, 2010).

Segundo Ugarte (2008), o ciberativismo está baseado em três vias: discurso, ferramentas e visibilidade. O discurso compreende uma forma de "hacking social", que parte da possibilidade de mudança do mundo e do empoderamento das pessoas, criando uma identidade que permite a união de desconhecidos. Em relação às ferramentas, o ciberativismo traz consigo o legado da cultura hacker do "faça você mesmo" e está ligado ao desenvolvimento de instrumentos que permitam as ações. Por último, a visibilidade é apontada enquanto o fim do ciberativismo, significando reconhecimento entre os ciberativistas e também visibilidade do coletivo na sociedade (Ugarte, 2008).

Na revisão do conceito de ciberativismo, Araújo e Freitas (2012) consideram tanto sua polissemia quanto as diferentes perspectivas teóricas e o definem como

\footnotetext{
"o conjunto de práticas realizadas em redes cibernéticas, com o objetivo de ampliar os significados sociais por meio da circulação na rede de discursos e de ferramentas capazes de colaborar na defesa de causas específicas. Trata-se de uma nova cultura de ligação com os assuntos de uma cidadania em contexto global" (Araújo e Freitas, 2012: 114).
}

Alguns eventos recentes contribuem para se compreender a importância do ciberativismo, principalmente a partir de 2011 , onde um novo momento de lutas se abriu após a queda dos ditadores na Tunísia e no Egito, que se deu porque revoltas contra regimes ditadores se espalharam pelo norte da África e pelo Oriente Médio. Na Europa, os "Indignados" ocuparam as praças centrais de Barcelona e Madrid, na Espanha. Outras ocupações e revoltas surgiram na Grécia, em outros países da Europa e nos Estados Unidos (Occupy Wall Street).

Em junho de 2013, foi a vez do Brasil, onde milhares de pessoas foram às ruas protestar contra o aumento das passagens de ônibus. Em todas estas mobilizações, as NTIC, as redes sociais digitais, bem como outros espaços de comunicação na internet, tiveram papel importante. Embora cada uma destas lutas se dê em contextos e por motivos muito diferentes, é possível estabelecer similitudes 
entre elas no que tange a forma de se fazer política utilizando as novas tecnologias (Alcântara, 2015). As práticas ativistas no ciberespaço criam um novo sujeito coletivo, mais complexo, capaz de produzir ações que podem criar uma nova dinâmica nas estruturas de poder e democratizar as políticas públicas, abrindo mais espaço para a atuação da sociedade civil (Castells, 2005).

Diante disso, este artigo apresenta a análise do ciberativismo socioambiental, a partir do estudo de duas experiências de movimentos socioambientais que utilizam o ciberespaço para a luta em defesa da saúde ambiente no contexto de instalação de indústrias petrolíferas no Brasil e na Espanha.

Os movimentos socioambientais analisados: o Fórum Suape e a Plataforma Ciudadana Refinería No

O Fórum Suape: espaço socioambiental é uma organização da sociedade civil articulada em um fórum permanente, instituído em 2013, que tem como objetivo discutir questões que estão sendo vivenciadas pelos povos residentes no entorno do Complexo Industrial Portuário de Suape (CIPS), localizado no litoral sul de Pernambuco, Região Nordeste do Brasil, entre os municípios de Ipojuca e Cabo de Santo Agostinho (figura 1).

A partir de 2007, mediante recursos oriundos do Programa de Aceleração do Crescimento (PAC), ganhou maior dinamicidade com a implementação de novos e grandes empreendimentos como a Refinaria Abreu e Lima (RNEST), o Estaleiro Atlântico Sul e a Petroquímica da Petrobras. Esses investimentos culminaram na ampliação e dinamização da infraestrutura local, transformando aqueles municípios, e as mais de 27 comunidades tradicionais, em verdadeiros canteiros de obras, sofrendo prejuízos de ordem econômica, material, cultural, simbólica e sanitária, além dos diversos impactos ambientais severos em virtude das profundas mudanças no território (Domingues et al., 2014; Santos et al., 2016).

Diante dos prejuízos decorrentes da instalação do CIPS, o Fórum Suape instituiu como missão "incentivar e promover processos de equidade social, direitos humanos e justiça ambiental na região afetada pelas rápidas transformações territoriais, sociais e ambientais decorrentes dos empreendimentos" (Fórum Suape, 2017: s/p).

A Plataforma Ciudadana Refinería No (PCRN), por sua vez, começou a se instituir como um movimento ambiental em 2005, por iniciativa dos moradores de Extremadura, região autônoma da Espanha (figura 2), fronteira com Portugal, cuja população gira em torno de um milhão de habitantes.

A Plataforma Ciudadana Refinería No se formou após o anúncio pelo governo local da aprovação da instalação de uma refinaria de petróleo na região
(Refinería Balboa) sem discussão democrática com a comunidade local (Plataforma Ciudadana Refinería No, 2013). Mediante a falta de socialização da informação sobre os efeitos negativos decorrentes da instalação de uma refinaria, o movimento teve como primeira diretriz o lema: "para opinar tem que estar adequadamente informado", e centrou sua atuação nos seguintes objetivos: (1) dar aos cidadãos uma informação objetiva e contrastada para que pudessem decidir o que querem para sua terra; (2) exigir dos partidos políticos o cumprimento de seus programas eleitorais que apoiavam os municípios no combate às alterações climáticas, na promoção de iniciativas públicas e privadas para a redução das emissões de gases de efeito de estufa e no desenvolvimento de fontes de energia renováveis. O movimento passou a exigir que toda declaração acerca da refinaria fosse respaldada em informações técnicas e científicas através do diálogo democrático com a sociedade da região.

Ambos os movimentos emergem pautados na ideologia do desenvolvimento sustentável, defendendo que o modelo econômico relacionado à construção de indústrias petrolíferas é incompatível com a preservação da vida e do planeta, pois os impactos não operam de forma linear, atingindo as pessoas de modo desigual e produzindo muitos danos irreversíveis.

A escolha desses movimentos sociais se deu por serem identificados em suas práticas de ciberativismo que mantém a tematização da saúde e ambiente no contexto de implantação de refinarias de petróleo, sendo um tomado como de referência do contexto europeu com experiência em passivos e problemáticas ambientais consistentes (Espanha) e outro, recente, em contexto de ausência de passivo ambiental relativo à planta de refinarias no estado de Pernambuco (Brasil).

\section{Percurso metodológico}

Trata-se de um estudo em base de dados secundários, conforme Gil (2009), cujo enfoque empírico foi desenhado como estudo de caso por ser o mais indicado para análise de uma realidade específica apropriado para analisar situações que envolvem contextos organizacionais, políticos e sociais particulares do caso, mas que tem potência para análise de outros casos semelhantes em que está envolvido um marco regulatório geral a ser aplicado em contextos particulares (Gil, 2009; Steban, 2010; Ventura, 2007). O estudo foi desenvolvido em três etapas:

a) revisão de literatura científica, que utilizou como buscadores os termos: ciberativismo, direito humano à comunicação, movimentos socioambientais, direito sanitário, direito à saúde, direito ambiental, e comunicação, saúde, ambiente. Como critérios de inclusão 


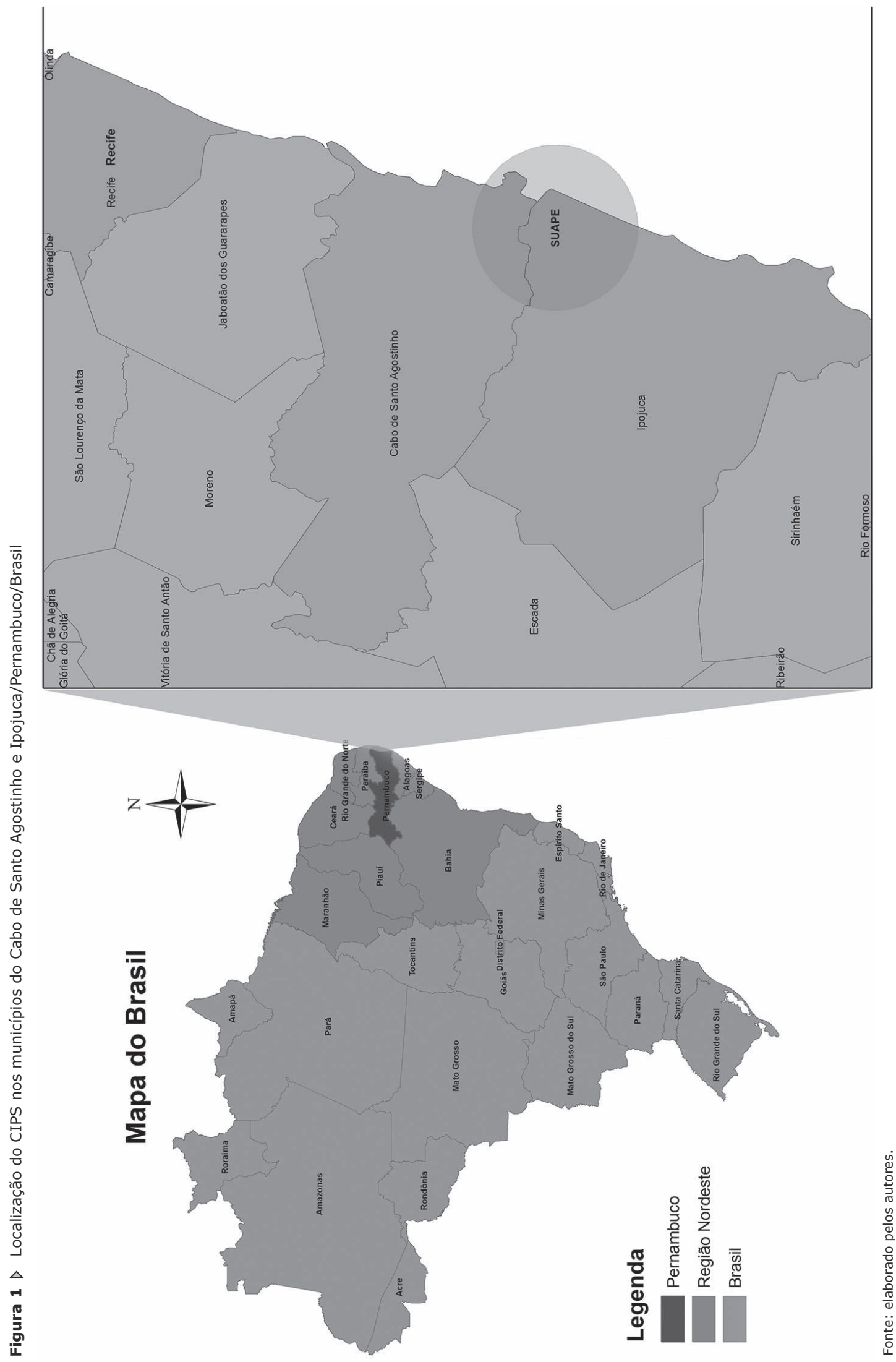




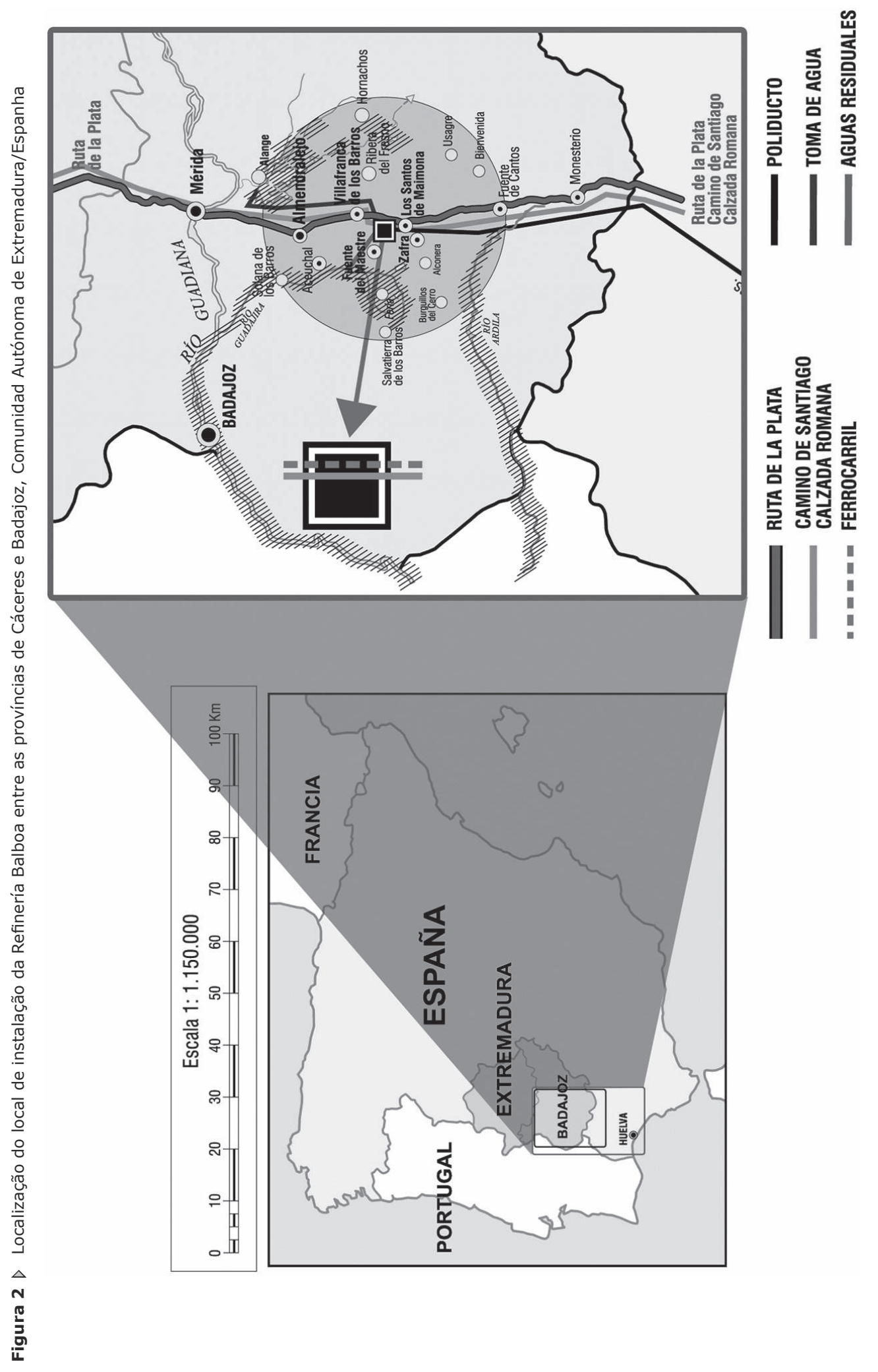

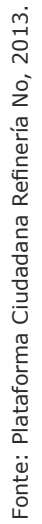


foram definidos: artigos científicos, relatórios e pareceres técnicos. Os critérios de exclusão foram: ausência de autoria, textos incompletos, textos que não abordassem o tema da saúde, ambiente e comunicação;

b) coleta de dados mediante análise das plataformas virtuais dos dois movimentos socioambientais, Plataforma Ciudadana Refinería No (PCRN) e Fórum Suape: espaço socioambiental (Fórum Suape), a partir de sua atuação na internet;

c) análise do ciberativismo socioambiental a partir da matriz modelizante para construção do Índice de Participação Política e Influência (IPPI).

A matriz modelizante proposta por Araújo, Penteado e Santos (2015) permite a construção do Índice de Participação Política e Influência (IPPI), identificando o grau de influência exercido pelas organizações da sociedade civil sobre o ciclo de políticas públicas e as experiências de ciberativismo. Esse índice avalia a heterogeneidade, apropriação de recursos da internet para a participação cidadã e políticas públicas. Foram estabelecidas cinco dimensões com base na literatura científica: usos e recursos da internet (D1); atores e capital social (D2); e-participação e estratégias de mobilização (D3); desdobramento da ação e relação com as políticas públicas (D4); e repercussão nos meios de comunicação tradicionais (D5).

No quadro 1 estão a descrição das dimensões de análise do IPPI e os critérios de mensuração de cada uma delas. Utilizou-se o software QSR NVivo 2.0 que permite a codificação, identificação de unidade de textos, realização de anotações, marcações e comentários relacionados. Após a codificação, os dados foram organizados em quadros para a apresentação dos resultados e a análise crítica correspondente.

\section{Resultados e discussão}

A militância e/ou ativismo no ciberespaço tornou-se uma das grandes estratégias dos dois movimentos socioambientais. Dessa forma, pode-se verificar as diversas formas e frentes de trabalho na busca da adesão das pessoas para o enfrentamento de propostas que põe em jogo a sustentabilidade do desenvolvimento humano e dos ecossistemas.

\section{D1: uso e recursos da internet}

O Fórum Suape utiliza o ciberespaço como mais um espaço para as lutas sociais, para articulação e divulgação dos problemas em Suape, contrapondo-se ao discurso desenvolvimentista neoliberal que apresenta apenas os desdobramentos benéficos para a população e o Estado, e cuja postura totalitária não deveria encontrar ressonância em uma democracia.

A sua página na internet foi estruturada em formato semelhante ao de algumas plataformas digitais sociais, pois possibilita grande interatividade nas discussões e publicações, sendo necessário efetivar um cadastro com criação de login e senha. Os usuários podem participar de salas virtuais de bate-papo, e realizar postagens de textos, fotos e vídeos. Esse cadastro também possibilita o envio de e-mail para todos os usuários, convidando para as atividades do movimento (Fórum Suape, 2017).

A página do Fórum ${ }^{1}$ possibilita ainda o acesso a textos, artigos, dissertações e teses sobre temas correlatos à causa, além do registro de denúncias das injustiças e da omissão dos órgãos gestores. 0 espaço virtual ganha, portanto, a força de um dispositivo regulador de fácil acesso, configurando-se em um espaço ágil de denúncia e mobilização de articulações populares tanto virtuais como reais.

O site da Plataforma Ciudadana, por sua vez, apresenta-se como um espaço para reunir os documentos construídos durante todo seu período de atuação e também para divulgar as ações e agendas. A página virtual foi organizada por subdivisões de temas - saúde, legislação, mobilização social, energia e meio ambiente - e seções diversas.

É importante levar em conta que, cada vez mais, as diversas redes sociais, dentre elas o Facebook, vêm sendo utilizadas como espaço comum de discussão e participação, onde as pessoas podem se agregar, debatendo e promovendo ações e ideias. Lemos (2004) afirma que esse tipo de espaço funciona de forma complementar ao espaço lugar, pois permite a criação de arenas monopolizadas anteriormente apenas pelos meios massivos de comunicação (Lemos, 2004). Tanto o Fórum Suape quanto a PCRN criaram perfis no Facebook para interação e mobilização com os atores sociais parceiros e população em geral, além do compartilhamento de assuntos de interesse comum, fotos, vídeos e chamadas para eventos.

A estratégia do audiovisual também está cada vez mais presente nos movimentos sociais, tanto pela facilidade tecnológica de produção (câmeras fotográficas e smartphones que possibilitam imagens em alta qualidade) como pela facilidade de veiculação e circulação na internet em plataformas como YouTube, Vimeo etc. Esse novo contexto incentiva os ativistas a produzirem seus próprios vídeos. Castells (2015) relata que o alcance do YouTube em 2007 o tornou o maior meio de comunicação do mundo, devido ao acesso também pelo celular. A produção e o consumo de vídeos se popularizaram, e despertam, muitas vezes, maior interesse do que a leitura de textos (Castells, 2015).

O Fórum Suape tem investido cada vez mais nessa estratégia, seu canal no YouTube tem mais 
Quadro $1 \triangleright$ Dimensões do Índice de Participação Política e Influência (IPPI), dimensões, descrição e mensuração

\begin{tabular}{|c|c|c|}
\hline Dimensões do IPPI & Descrição & Mensuração \\
\hline $\begin{array}{l}\text { D1: Uso dos recursos da } \\
\text { internet }\end{array}$ & $\begin{array}{c}\text { Identificação e avaliação } \\
\text { dos dispositivos } \\
\text { comunicacionais } \\
\text { que o grupo/coletivo utiliza } \\
\text { em uma ação ativista }\end{array}$ & $\begin{array}{l}0 \text { - não utiliza recursos da internet } \\
1 \text { - apenas utiliza um site } \\
2 \text { - utiliza, além do site, redes sociais, YouTube } \\
\text { - o site oferece ferramentas, aplicativos e dispositivos para a mobilização e debate } \\
\text { sobre temas correlacionados a PP } \\
4 \text { - o site e redes sociais oferecem ferramentas, aplicativos e dispositivos para a mobili- } \\
\text { zação e debate sobre temas correlacionados a PP } \\
5 \text { - os usuários podem participar da produção de propostas e ações do grupo ciberativista }\end{array}$ \\
\hline $\begin{array}{l}\text { D2: Atores envolvidos } \\
\quad \text { e capital social }\end{array}$ & $\begin{array}{c}\text { Identificação e classificação } \\
\text { dos atores envolvidos } \\
\text { quanto ao seu capital social } \\
\text { para a mobilização de } \\
\text { recursos financeiros } \\
\text { e mobilização de pessoas }\end{array}$ & $\begin{array}{l}0 \text { - os atores envolvidos não possuem ligações com outros grupos ou instituições } \\
1 \text { - os atores envolvidos pertencem a uma rede de movimentos sociais locais/regionais } \\
2 \text { - os atores envolvidos pertencem a uma rede de movimentos sociais nacionais } \\
3 \text { - os atores envolvidos pertencem a uma rede de movimentos sociais internacionais } \\
4 \text { - os atores envolvidos pertencem a uma rede de movimentos sociais e possuem víncu- } \\
\text { los com instituições públicas } \\
5 \text { - os atores envolvidos pertencem a uma rede de movimentos sociais, possuem vínculos } \\
\text { com instituições públicas e atuam dentro dos mecanismos de representação política }\end{array}$ \\
\hline $\begin{array}{c}\text { D3: E-participação } \\
\text { e estratégias de mobilização }\end{array}$ & $\begin{array}{c}\text { Identificação e classificação } \\
\text { das formas de webativismo } \\
\text { (e-participação, } \\
\text { com base nas categorias } \\
\text { desenvolvidas por Araújo, } \\
\text { Penteado, Santos, 2013, e } \\
\text { Tamborius et al., 2007) e } \\
\text { uso dos recursos } \\
\text { do ciberespaço } \\
\text { para a mobilização }\end{array}$ & $\begin{array}{l}0 \text { - e-informação: há apenas informação para cidadãos; não há interatividade, a página } \\
\text { não encoraja o engajamento da sociedade na causa em questão } \\
1 \text { - e-consulta: possibilita o recolhimento de informações do público em geral; as ações } \\
\text { utilizam ferramentas básicas como envio de e-mails e enquetes; há o encorajamento } \\
\text { da mobilização apenas por meio de informações publicadas na página } \\
\text { 2- e-mobilização: há ação de estímulo e convocação na defesa de valores e ideias; uso } \\
\text { de eventos do Facebook e outras formas de interação e mobilização nas redes sociais } \\
\text { - e-engajamento: além das características acima, os cidadãos defendem suas ideias } \\
\text { e valores em detrimento de outros; presença de convocação em cascata e uso de } \\
\text { torpedos, além do uso das redes sociais } \\
4 \text { - e-deliberação: a ação auxilia na resolução de impasses, tomadas de decisão a partir } \\
\text { de discussão e debate entre atores políticos; a mobilização ocorre por meio de uma } \\
\text { somatória de estratégias que envolvem o uso das TIC e, em alguns casos, o uso dos } \\
\text { meios de comunicação de massa } \\
5 \text { - e-empoderamento: há transferência de influência, controle, proposição e formulação } \\
\text { de políticas a partir dos desejos e anseios dos cidadãos; ocorrem ações de mobilizçáo } \\
\text { com utilização das ferramentas tecnológicas e meios de comunicação de massa, além } \\
\text { do desenvolvimento de ações off-line de conscientização e promoção do engajamento } \\
\text { social }\end{array}$ \\
\hline $\begin{array}{c}\text { D4: Desdobramentos } \\
\text { da ação e relação com PP }\end{array}$ & $\begin{array}{c}\text { Verificar se após } \\
\text { a realização de uma ação } \\
\text { ou mobilização houve } \\
\text { um desdobramento político: } \\
\text { proposta de uma política } \\
\text { pública, influência } \\
\text { na formação da agenda etc. }\end{array}$ & $\begin{array}{l}0 \text { - as ações não são consideradas pelo poder público } \\
1 \text { - as ações são incorporadas a discursos, mas não são incluídas em projetos ou } \\
\text { programas de governo } \\
2 \text { - as ações são incorporadas a projetos novos ou influenciam a revisão e avaliação de } \\
\text { agendas do governo } \\
\text { - as ações são determinantes para a formação da agenda de governo e influenciam } \\
\text { novos projetos e planos de metas para a gestão } \\
4 \text { - as ações implicam a elaboração própria de políticas que são incorporadas pelos } \\
\text { governos. O governo mantém para si a tarefa de implementação e avaliação } \\
5 \text { - as ações implicam a elaboração de diretrizes e projetos por parte da sociedade civil } \\
\text { que são incorporadas pelo governo. O Estado permite o envolvimento da sociedade } \\
\text { civil também na implementação e avaliação do projeto }\end{array}$ \\
\hline $\begin{array}{l}\text { D5: Repercussão nos meios } \\
\text { tradicionais de comunicação } \\
\text { massiva }\end{array}$ & $\begin{array}{l}\text { Identificar se a ação } \\
\text { ou mobilização teve } \\
\text { repercussão nos meios } \\
\text { tradicionais e dentro } \\
\text { do ciberespaço }\end{array}$ & $\begin{array}{l}0 \text { - não há repercussão nos meios tradicionais } \\
1 \text { - ocorrem referências indiretas da ação em jornais e/ou revistas impressas de bairro } \\
\text { e/ou de circulação local } \\
2 \text { - ocorrem referências diretas à ação em jornais e/ou revistas impressas de bairro e/ou } \\
\text { de circulação local } \\
\text { - ocorrem referências indiretas à ação em meios de comunicação eletrônicos tradicio- } \\
\text { nais (rádio e TV) com ou sem referências a periódicos impressos } \\
4 \text { - ocorrem referências diretas à ação em meios de comunicação eletrônicos tradicionais } \\
\text { (rádio e TV) com ou sem referências a periódicos impressos } \\
5 \text { - as ações são noticiadas e/ou comentadas de forma direta por meios eletrônicos e } \\
\text { impressos com enquadramento propositivo, chamando a atenção do poder público }\end{array}$ \\
\hline
\end{tabular}

Fonte: Araújo et al., 2015.

de 30 vídeos classificados em palestras, teasers e depoimentos, todos de produção própria (documentário Suape, um caminho sinuoso e Suape), pelos moradores das comunidades envolvidas no movimento ou de grupos parceiros denunciando os atos de violência cometidos pela polícia na desapropriação de suas casas. Já o canal do YouTube da PCRN conta com mais de 90 vídeos, entre atos políticos, passeatas, shows de música, sendo o mais antigo de setembro de 2008 e o mais atual de abril de 2015. Também foram identificados no site muitos vídeos postados por outros usuários ligados ao movimento social, muitas vezes vídeos simples, em estilo slideshow. Merece citação o documentário produzido pelo Canal Extremadura TV, em 2013, intitulado El Lince com botas 3.0: Las razones del $n o^{2}$, que mostra toda a luta do movimento. Lemos (2004) ressalta que as diversas ferramentas da internet podem mobilizar pessoas e colaborar na organização de movimentos, na difusão da infor- 
Quadro $2 \triangleright$ Índice de Participação Política e Influência. Fórum Suape: espaço socioambiental e Plataforma Ciudadana Refinería No, 2016

\begin{tabular}{|c|c|c|}
\hline Dimensões do IPPI & $\begin{array}{c}\text { Plataforma } \\
\text { Ciudadana Refinería No }\end{array}$ & Fórum Suape \\
\hline 1. Uso dos recursos da internet & 5 & 5 \\
\hline 2. Atores envolvidos e capital social & 5 & 5 \\
\hline $\begin{array}{l}\text { 3. Tipos de webativismo (E-participação e estratégias } \\
\text { de mobilização) }\end{array}$ & 5 & 5 \\
\hline 4. Desdobramento da ação e relação com políticas públicas & 3 & 2 \\
\hline 5. Repercussão nos meios massivos tradicionais & 4 & 1 \\
\hline
\end{tabular}

Fonte: elaborado pelos próprios autores.

mação por intermédio da articulação em rede, de modo descentralizado e colaborativo, uma vez que as pessoas podem interagir com movimentos de qualquer parte do mundo em tempo real. O desenvolvimento de redes horizontais de comunicação interativa que ligam o local e o global possibilitam às pessoas a apropriação de novas formas de se comunicar e atuar, como se pode verificar nos dois movimentos socioambientais analisados.

\section{D2: atores e capital social}

Segundo Materleto (2001), uma rede social representa "um conjunto de participantes autônomos, unindo ideias e recursos em torno de valores e interesses compartilhados" e forma um complexo sistema social que estrutura as relações entre atores no interior de grupos e organizações específicas ao movimento e suas relações político-institucionais. Ao descrevê-las é possível apreender como elas influenciam o comportamento social e conseguem produzir mudança (Fontes, 2007; Marteleto, 2001). Nesse sentido, tanto o Fórum Suape quanto o PCRN constituem uma ampla rede de atores sociais, conforme descreveremos a seguir.

O Fórum Suape é composto por pessoas físicas e instituições. Participam pesquisadores de diversos campos do conhecimento: Associação dos Geógrafos Brasileiros, Universidade Federal de Pernambuco (UFPE), Federação de Órgãos para Assistência Social e Educacional (FASE), Fundação Oswaldo Cruz Pernambuco (Fiocruz); lideranças de comunidades tradicionais (Conselho Pastoral dos Pescadores NE II, associações de pescadores e moradores), lideranças de organizações não governamentais (ONG) envolvidas em temáticas específicas, tais como gênero, direitos humanos, meio ambiente, questões fundiárias (Centro das Mulheres do Cabo, Associação Brasileira de Agroecologia, ActionAid, Comissão Pastoral da Terra - CPT, Movimento dos Trabalhadores Rurais Sem Terra - MST).

Além das redes locais, o Fórum se articula com redes nacionais, como a Rede Brasileira de Justiça Ambiental (RBJA), e instituições não governamentais internacionais, como Both $\mathrm{ENDS}^{3}, \mathrm{SOMO}^{4}, \mathrm{OCDE}$ Watch $^{5}$, Conectas Direitos Humanos ${ }^{6}$, International Service for Human Rigths (ISHR) ${ }^{7}$, que têm sido importantes na formação do capital social, seja através de apoio financeiro aos projetos de ação do Fórum, seja na internacionalização da luta por meio de denúncias das empresas multinacionais que atuam no CIPS.

Já a PCRN foi composta por atores da sociedade civil, definidos pelo movimento como cidadãos livres que valorizam a qualidade de vida para além de aspectos meramente econômicos e que não possuem interesses ocultos, sendo contra indústrias contaminantes (Plataforma Ciudadana Refinería No, 2005). Mulheres, trabalhadores, jovens, agricultores, pesquisadores também fazem parte desse movimento, que instituiu um coletivo que se reunia semanalmente no colégio público José Rodríguez Cruz, em Villafranca de los Barros (Badajoz), para discussões e planejamento de suas atividades. À medida que foi se consolidando, aumentaram as adesões de grupos populares provenientes de diversos segmentos, como atores, músicos, artistas, escritores, donas de casa, crianças, jornalistas, radialistas, associação de moradores campesinos - caso da Associação de Amigos da Via de la Plata e do Caminho de Santiago - e partidos políticos de esquerda.

Nesses dois movimentos sociais de caráter direto e descentralizado, a articulação territorial, através de redes sociais, para a busca de caminhos alternativos à submissão imposta pelo mercado mundial é uma realidade, uma vez que se ampliam as possibilidades de organização de práticas sociais na construção de processos coletivos para o desenho de caminhos alternativos, participativos, criativos e emancipatórios que conduzam a luta contra-hegemônica, em favor de uma sociedade democrática, mais justa e igualitária.

D3: tipos de webativismo (e-participação
e estratégias de mobilização)

O Fórum Suape busca dar visibilidade e resolutividade aos conflitos que estão emergindo, por 
isso, oferece ajuda política e jurídica aos problemas identificados, através de ações de mobilização articuladas com lideranças comunitárias do território e agendamento de audiências no Ministério Público, que versam, dentre outros temas, sobre os processos de expulsão de moradores de suas terras ou pagamentos de indenizações irrisórias, muito abaixo de valores de mercado, processo caracterizado pela desterritorialização das comunidades.

Apesar das dificuldades que o movimento enfrenta na formação de agendas de adesão ou simplesmente no diálogo com instituições governamentais e empresas que atuam no território de Suape - para discussão dos principais problemas enfrentados, como, por exemplo, a violência da polícia e atuação de milícias na expulsão de moradores de suas casas, a contaminação das águas (das fontes de abastecimento para o consumo da população e do mar), do solo e do ar, decorrentes de obras estruturais como a dragagem para aprofundamento do canal do porto -, o site apresenta um alto grau de engajamento na formação de agendas e diálogos com os sujeitos afetados pelo CIPS ou comprometidos com o movimento. Isso é observado mediante a diversidade de vozes em diferentes espaços da página, o que acaba ocorrendo devido ao formato do site, que disponibiliza salas de bate-papo e uma participação ativa de quem o acessa.

Essa organização facilita a formação de mobilizações a partir das discussões realizadas no espaço virtual e fomenta agendamento de encontros presenciais. O acervo construído coletivamente no site também subsidia o envolvimento dos diferentes grupos do território sobre os acontecimentos vivenciados e como fonte de informação para ação e tomada de decisão (blog de notícias, informativo mensal, vídeos, fotos, estudos, textos diversos), oferecendo ainda uma configuração de rede social, que permite que seus membros também possam conversar e postar matérias e conteúdos. O Fórum tem uma página no Facebook (https://www.facebook.com/fsuape/), que facilita a interação e a organização das mobilizações.

O Movimento PCRN se organizou por meio de diversas estratégias como passeatas, manifestações, shows musicais, feira de alimentos produzidos pelas comunidades, fóruns temáticos, além da elaboração de relatórios e estudos sobre o universo do petróleo, meio ambiente, mudança climática, energias renováveis e saúde por especialistas de universidades e centros de pesquisa, tanto para obter o respaldo científico quanto para compreender a amplitude dos problemas que uma refinaria pode causar e assim efetivar a troca de saberes com os demais moradores sobre o futuro do seu território (Plataforma Ciudadana Refinería No, 2013).

Para pressionar os representantes e investidores do projeto da refinaria, para que o projeto não fosse implantado na região, o movimento PCRN buscou várias fontes de informação para compreender as transformações que uma refinaria poderia produzir em seu território, e a partir disso construíram estratégias comunicativas para mobilizar o maior número de pessoas.

Conforme relato no primeiro livro do movimento, intitulado La salud, la dignidad y la información dan la libertad al ciudadano (Plataforma Ciudadana Refinería No, 2005), como a cobertura das atividades da PCRN pelos meios de comunicação tradicionais era dificultada pela pressão dos grupos favoráveis à Refinería Balboa e pelo desconhecimento dos reais problemas que a indústria do petróleo causaria na região, eles utilizaram a internet para realizar ativismo e mobilização da população durante a intensa campanha para o impedimento da construção da refinaria. O objetivo era provocar o envolvimento da sociedade civil nas decisões do Estado e, para tal, realizaram atividades políticas, culturais e educativas numa gama de formatos e possibilidades: manifestações, concentrações assembleias, caminhadas, concertos musicais, exposições, feiras, protestos em eventos nacionais e internacionais, visita às instituições de defesa dos direitos humanos internacionais.

Em julho de 2012 o movimento conseguiu impedir a construção da Refinería Balboa. A Declaração de Impacto Ambiental, publicada pelo Ministério da Agricultura, Pesca, Alimentação e Meio Ambiente espanhol, reconheceu a inviabilidade da instalação da refinaria, em razão dos grandes impactos, que afetariam não somente o local do empreendimento, mas toda a região do entorno. Segundo a Plataforma, esse talvez tenha sido o único movimento popular a conseguir que os desejos da sociedade civil fossem incorporados pelo governo de forma tão emblemática e significativa: o cancelamento do projeto da refinaria (Plataforma Ciudadana Refinería No, 2013).

D4: desdobramento da ação e relação com políticas públicas

No caso da PCRN, diante das fortes pressões sociais, a exigência da sociedade civil organizada foi incorporada na agenda das políticas públicas, consequentemente, a refinaria não foi construída. Essa pressão proveniente de uma consciência cidadã que foi instituída por meio do conhecimento e da compreensão de que a refinaria não iria melhorar a vida e nem a economia da região foi fundamental para o exercício da cidadania na construção compartilhada das políticas públicas. O estímulo à consciência ecológica e a importância do sujeito empoderado nos processos decisórios, neste caso, foram fundamentais para o êxito do movimento.

Nessa dimensão, a PCRN apresentou melhor pontuação que o Fórum Suape. No caso do movi- 
mento brasileiro, a relação com as políticas públicas tem sido bastante conturbada e de difícil incorporação na agenda política das ações pleiteadas pelo Fórum. Mesmo assim, alguns espaços foram conquistados junto a instituições importantes, como o Ministério Público e Assembleia Legislativa, porém, ainda de forma bastante incipiente.

Essa diferença entre os movimentos, caracterizada pela baixa efetividade no alcance de políticas públicas pelo Fórum Suape, pode ser explicada, dentre outros fatores, pelo baixo grau de coesão social que sua sociedade compartilha, a dificuldade em articular diferentes comunidades e realidades em um grande território frente às dificuldades vivenciadas em períodos distintos. A coesão social, que pode ser definida e caracterizada pelo compartilhamento de sentido de pertencimento e inclusão a um território, e a participação ativa nos assuntos públicos e o gozo de equidade no acesso aos bens e serviços públicos, juntamente com a distribuição igualitária das oportunidades e da riqueza, tudo isso, num ambiente onde as instituições geram confiança e legitimidade. Aliado a isso, a forte presença do Estado como o ator principal das vulnerabilizações socioambientais vivenciadas e ao mesmo tempo ausente em espaços de discussão participativa.

\section{D5: repercussão nos meios de comunicação social}

A PCRN organizou um livro contendo uma coletânea de textos jornalísticos publicados sobre as mobilizações, além das estratégias utilizadas, como passeatas, manifestações, fóruns temáticos, produção de vídeos, elaboração de estudos ambientais e campanhas educativas e culturais fomentando a troca de saberes. Obtiveram alguma repercussão do tema nos veículos de comunicação tradicionais, como jornais impressos, digitais de grande circulação e da televisão local. Mas essa visibilidade na imprensa não surgiu como apoio, na verdade, era a cobertura das mobilizações maiores que repercutiam no território.

O Fórum Suape, assim como o PCRN, não tem grande destaque nos meios de comunicação em massa tradicionais. É baixa ou nenhuma a repercussão em veículos de comunicação, como rádio, jornais impressos e televisão. Isso ocorre devido, dentre outros fatores, à dominação dos meios de comunicação por grupos de interesse favoráveis ao modelo desenvolvimentista do capital, em que grupos vulneráveis são excluídos do processo de discussão e decisão sobre o seu território, como as populações tradicionais de povos indígenas, comunidades quilombolas, agricultores e pescadores artesanais, onde tais vozes muitas vezes são abafadas, desconsideradas ou deturpadas pela grande imprensa, que propagandeia apenas o bônus dos empreendimentos econômicos e oculta o ônus social, fragilizando as comunidades e os seus territórios.

\section{Considerações finais}

Dentre as estratégias de enfrentamento dos processos de injustiça e vulnerabilização socioambiental, as NTIC têm bastante relevância, pois possibilitam aprendizado, produção de conhecimento, troca de saberes, formas e expressões de vida, e tornam os problemas visíveis, facilitando que mais atores e instituições se articulem para a resolução problemas e alcance de objetivos em comum. Isso favorece que sujeitos e comunidades, antes excluídos dos processos de visibilidade social, possam ter um papel ativo de cidadania e nos processos decisórios, como pode ser visto em ambos os movimentos analisados, que tecem seus argumentos apoiando-se nos conceitos de cidadania, de justiça ambiental e de desenvolvimento sustentável.

O movimento ciberativista espanhol construiu estratégias de mobilização em rede, dentro e fora da internet, conseguindo dar a visibilidade que o movimento pretendia, rompendo os limites geográficos e conseguindo promover o sentimento de coletivização e de pertencimento dos envolvidos no processo.

O movimento brasileiro guarda um contexto de enfrentamento significativamente distinto. Aqui, alguns dos desafios ainda estão postos, como ficou evidente quando aplicamos o IPPI. Alguns desafios e campos para o seu fortalecimento devem ser considerados, como a conquista e a adesão de novos atores sociais à conscientização cidadã e ecológica; a ampliação e o estabelecimento de um diálogo participativo e efetivo na elaboração de políticas pelo poder público sobre o seu território e o fortalecimento e ampliação das conquistas do Fórum como um ambiente privilegiado de atuação no ciberativismo, ampliando as possibilidades de organização de práticas sociais participativas na construção de processos coletivos e na efetiva comunicação em rede.

Esses caminhos alternativos, participativos, criativos e emancipatórios conduzem à luta contra-hegemônica, em favor de uma sociedade democrática mais justa e igualitária. Ambos os movimentos ciberativistas têm conseguido formular e pôr em prática estratégias de comunicação alternativas aos meios de comunicação tradicionais, e têm alcançado resultados positivos, influenciando políticas públicas em maior ou menor grau.

Como desafio, os ativistas precisam explorar o potencial das NTIC conhecendo melhor suas ferramentas, como nas palavras de Castells (2003: 10), "apropriando-a, modificando-a e experimentando-a", buscando, nessas novas possibilidades de comunicação, maior visibilidade, mediante o reconhecimento público, no sentido de mobilizar os cidadãos direta ou indiretamente envolvidos com o problema e que 
compartilham os mesmos objetivos e ideais, promovendo assim o sentimento de coletivização de forma dialógica, libertadora e educativa, em busca da preservação do direito humano à comunicação em situações de potenciais danos ao ambiente e à saúde.

\section{Notas}

1 www.forumsuape.ning.com.

2 http://www.canalextremadura.es/alacarta/tv/videos/ el-lince-30-las-razones-del-no-260513.

3 http://www.bothends.org.

4 http://www.somo.nl.

5 http://www.oecdwatch.org.

6 http://www.conectas.org.

7 http://www.ishr.ch.

\section{Referências bibliográficas}

ALCÂNTARA, L. M. de (2015), "Ciberativismo e movimentos sociais: mapeando discussões", Aurora: Revista de Arte, Mídia e Política, 8 (23), pp. 73-97.

ARAúJO, R. P. A., C. L. C. Penteado and M. B. P. dos Santos (2015), "Democracia digital e experiências de e-participação: webativismo e políticas públicas", História, Ciências, Saúde-Manguinhos, 22 (Suppl.), pp. 1597-1619. DOI: 10.1590/S010459702015000500004.

ARAÚJO, W. F. e E. C. de Freitas (2012), "'Quanto custa mudar o mundo?' Análise da dimensão discursiva do ciberativismo na WikiLeaks", Fronteiras - Estudos Midiáticos, 14 (2), pp. 110-120. DOI: 10.4013/ fem.2012.142.05.

BRASIL (2013), 7. Balanço Programa Aceleração do Crescimento - Eixo energia, Brasília-DF. http://www. pac.gov.br/pub/up/pac/7/05-PAC7_energia.pdf.

BRINGEL, B. e E. E. Muñoz (2010), "Dez anos de Seattle. O movimento antiglobalização e a ação coletiva transnacional", Ciências Sociais Unisinos, 46 (1), pp. 28-36. DOI: 10.4013/csu.2010.46.1.04.

CASTELLS, M. (2003), A galáxia da internet, Rio de Janeiro, Jorge Zahar.

CASTELLS, M. (2005), "A sociedade em rede", in M. Castells e G. Cardoso (coords.), A sociedade em rede. Do conhecimento à ação política, Lisboa, Fundação Calouste Gulbenkian, p. 435. http:// www.cies.iscte.pt/linhas/linha2/sociedade_rede/ zip/Sociedade_em_Rede_cC.zip.

CASTELLS, M. (2015), o poder da comunicação, São Paulo/Rio de Janeiro, Editora Paz e Terra.

CAVALCANTI, C. (2008), "Desenvolvimento e meio ambiente: o conflito do complexo industrial-portuário de Suape, Pernambuco", IV Encontro Nacional da Anppas, Brasília-DF. http://www. anppas.org.br/encontro4/cd/ARQUIVOS/GT2-633327-20080519205905.pdf.
CHESNAIS, F. e C. Serfati (2003), "'Ecologia' e condições físicas da reprodução social: alguns fios condutores marxistas", Revista Crítica Marxista, 1 (16), pp. 39-75. http://www.ifch.unicamp.br/criticamarxista/arquivos_biblioteca/artigo9539_merged.pdf.

DOMINGUES, R. C., et al. (2014), "A vulneração socioambiental advinda do complexo industrial portuário de Suape: a perspectiva dos moradores da Ilha de Tatuoca - Ipojuca/PE," Revista Tempus Actas de Saúde Coletiva, 8 (2), pp. 69-91. DOI:10.18569/ tempus.v8i2.1513.

FONTES, B. A. S. M. (2007), "Redes sociais e saúde: sobre a formação de redes de apoio social no cotidiano de portadores de transtorno mental", Política \& Trabalho: Revista de Ciências Sociais, (26), pp. 87-104. http://www.nucleodecidadania.org/nucleo/ extra/2007_07_16_06_10_51.pdf.

FÓRUM SUAPE (2017), Fórum Suape. http://forumsuape.ning.com.

GIL, A. C. (2009), Como elaborar projetos de pesquisa, São Paulo, Atlas.

GUARESHI, P. A. (2013), O direito humano à comunicação - Pela democratização da mídia, Petrópolis, Editora Vozes.

GURGEL, A. do M., et al. (2009), "Framework dos cenários de risco no contexto da implantação de uma refinaria de petróleo em Pernambuco", Ciência \& Saúde Coletiva, 14 (6), pp. 2027-2038. DOI:10.1590/S1413-81232009000600010.

LEMOS, A. (2004), "Cidade-ciborgue: a cidade na cibercultura", Galáxia, (8), pp. 129-148.

MARQUES, K. K. D. (2014), "Moradores invisíveis: o sofrimento social dos moradores da Ilha de Tatuoca, Ipojuca - PE, em seu processo de desterritorialização", Centro de Pesquisas Aggeu Magalhães/Fiocruz. http://www.cpqam.fiocruz. br/bibpdf/2014marques-kkd.pdf.

MARTELETO, R. M. (2001), "Redes sociais, mediação e apropriação de informaçõoes: situando campos, objetos e conceitos na pesquisa em ciência da informação", Pesquisa Brasileira em Ciência da Informação, 3 (1), pp. 27-46. http://www. mendeley.com/research/redes-sociais-media??o-e-apropria??o-informa??oes-situando-campos-objetos-e-conceitos-na-pesquisa-em/.

PACHECO, T. e M. F. Porto (2009), "Conflitos e injustiça ambiental em saúde no Brasil", Tempus - Actas de Saúde Coletiva, 4 (4), pp. 26-37. http://www. tempusactas.unb.br/index.php/tempus/article/ viewFile/742/752

PERUZZO, C. M. K. (2010), "A comunicação nos movimentos sociais: exercício de um direito", Diálogo de La Comunicación, 82 (V), pp. 1-7.

PLATAFORMA CIUDADANA REFINERÍA NO (2005), La salud, la dignidad y la información dan la libertad al ciudadano, Plataforma Ciudadana Refinería No.

PLATAFORMA CIUDADANA REFINERÍA NO (2013), EI imperador estaba desnudo - Crónica de la lucha ciudadana contra uma refinería de petróleo em 
Extremadura, Villafranca de los Barros - España, Imprenta Raeygo.

RIGOTTO, R. M. (2007), "'Caiu na rede, é peixe!': a industrialização tardia e suas implicações sobre o trabalho, o ambiente e a saúde no Estado do Ceará, Brasil", Cad. CRH 23, 4 (Suppl.), pp. 599-611.

RIGOTTO, R. M. (2008), Desenvolvimento, ambiente e saúde: implicações da (des)localização industrial, Rio de Janeiro, Editora Fiocruz.

SANTOS, M. O. S. dos, et al. (2012), "Análise crítica do discurso da mídia impressa sobre a saúde e o ambiente no contexto da instalação da refinaria de petróleo em Suape, PE", Reciis, 6 (4). DOI: 10.3395/reciis.v6i4.Sup1.724pt.

SANTOS, M. O. S. dos, et al. (2016), "Excluídas pelo desenvolvimento: mulheres e o complexo industrial portuário de Suape", Revista de Geografia (Recife), 33 (3), pp. 117-140. http://www.revista.ufpe.br/ revistageografia.
SILVA, J. M. da; L. G. da S. Augusto e I. D. Gurgel (2013), "Saúde do trabalhador nos estudos de impactos de refinarias de petróleo", Cadernos Saúde Coletiva, 21 (3), pp. 325-331.

SILVEIRA, S. A. da (2010), "Ciberativismo, cultura hacker e o individualismo colaborativo", Revista USP, (86), p. 28. DOI:10.11606/issn.2316-9036. v0i86p28-39.

STEBAN, M. P. S. (2010), Pesquisa qualitativa em educação: fundamentos e métodos, Porto Alegre, McGraw Hill/Artmed.

UGARTE, D. de (2008), O poder das redes: manual ilustrado para pessoas, organizações e empresas, chamadas a praticar o ciberativismo, Porto Alegre, EDIPUCRS.

VENTURA, M. M. (2007), "O estudo de caso como modalidade de pesquisa", Revista SOCERJ, 20 (5), pp. 383-286. http://www.rbconline.org. br/wp-content/uploads/a2007_v20_n05_art10.pdf.

Recebido a 31/03/2017. Aceite para publicação a 24/10/2017.

Mariana Olívia Santana dos Santos (marianaxolivia@gmail.com). Fundação Oswaldo Cruz, Instituto Aggeu Magalhães, Laboratório de Saúde, Ambiente e Trabalho. Av. Moraes Rego, s/n, Campus da UfPE - Cidade Universitária, 50670-420 Recife/PE, Brasil.

Thialisson Santos Ribeiro (thialisson_ribeiro@hotmail.com). Fundação Oswaldo Cruz, Instituto Aggeu Magalhães, Laboratório de Saúde, Ambiente e Trabalho. Av. Moraes Rego, s/n, Campus da UFPE - Cidade Universitária, 50670-420 Recife/PE, Brasil.

José Marcos da Silva (kinhoventuras@hotmail.com). Fundação Oswaldo Cruz, Instituto Aggeu Magalhães, Laboratório de Saúde, Ambiente e Trabalho. Av. Moraes Rego, s/n, Campus da UFPE - Cidade Universitária, 50670-420 Recife/PE, Brasil.

Isaltina Maria de Azevedo Mello (isaltina@gmail.com). Universidade Federal de Pernambuco, Departamento de Comunicação Social. Av. Prof. Moraes Rego, 1235 - Cidade Universitária, 50670-901 Recife/PE, Brasil.

Idê Gomes Dantas Gurgel (ideg@cpqam.fiocruz.br). Fundação Oswaldo Cruz, Instituto Aggeu Magalhães, Laboratório de Saúde, Ambiente e Trabalho. Av. Moraes Rego, s/n, Campus da UFPE - Cidade Universitária, 50670-420 Recife/PE, Brasil.

Lia Giraldo da Silva Augusto (Igiraldo@uol.com.br). Fundação Oswaldo Cruz, Instituto Aggeu Magalhães, Laboratório de Saúde, Ambiente e Trabalho. Av. Moraes Rego, s/n, Campus da UFPE - Cidade Universitária, 50670-420 Recife/PE, Brasil. 